\title{
APPLICATION OF TAGUCHI OPTIMIZATION METHOD IN THE PREPARATION OF ACTIVATED CARBON BY MICROWAVE TREATMENT
}

\author{
Oleg Petuhov \\ Institute of Chemistry of Academy of Science of Moldova, 3, Academiei str., Chisinau MD-2028, Republic of Moldova, \\ e-mail: petuhov.chem@gmail.com; phone: (+373 22) 7254 90; fax: (+373 22) 739954
}

\begin{abstract}
This paper reports on the preparation of activated carbon from walnut shell. Orthogonal array experimental design method was used to optimize the preparation of activated carbon with phosphoric acid by using microwave treatment. The optimization parameters were: microwave power, activation time, phosphoric acid concentration and particle sizes of nut shells. Thermal analysis of the intact and impregnated with phosphoric acid walnut shells was used for the simulation of activation process. Activated carbon with the optimal parameters was obtained, being characterized by gas adsorption method and scanning electron microscopy.
\end{abstract}

Keywords: activated carbon, walnut shells, microwave radiation, experimental design, analysis of variance.

Received: March 2015/ Revised final: April 2015/ Accepted: April 2015

\section{Introduction}

Widespread use of activated carbon (AC) in different areas continues to maintain interest in the increase of its production. Along with this, requirements are growing to the quality of AC. The high number both of methods of activation and AC precursors makes possible diversification and optimization of the processes of their obtaining. Currently tendencies are known for obtaining AC from cheap and renewable raw materials [1] and by methods with low energy consumption, as well [2]. Literature data indicate that nowadays AC is obtained from a variety of precursors, such as waste, both of natural [1] and synthetic origin [3], in addition to the traditional ones (wood, coal, nut shells). The process of obtaining AC involves an increased consumption of energy; therefore development of methods aimed at reducing energy consumption represents an important direction of investigations. A perspective research line in this context is the use of microwaves in the process of AC preparation [2, 4].

The employment of microwaves finds a widening application in various fields [5, 6]. This is explained by many advantages of microwave heating, in comparison with traditional methods. Rapid heating, lack of inertia in heat transfer and reduced activation time [4], which in turn leads to diminished consumption of energy and activation agents, are amongst the main advantages of its usage. Apart from obvious advantages, the following drawbacks of this method can be revealed: non-carbonized raw material weakly absorbs microwaves [7, 8]; materials that are used for production of the activation reactors in laboratory are not appropriate for their application at industrial level and existence of a maximum threshold, up to which substance can be heated. Nevertheless, some successful attempts of obtaining AC by microwave treatment on semi-industrial scale have been registered [9]. The listed problems were solved via carbonization the raw material by traditional heating; use of ceramic activation reactor and optimization the activation requirements.

In order to get optimized conditions for AC preparation, a large number of experiments must be carried out, since there are many variables determining the final AC parameters. Experimental design technique is an effective statistical method, which allows setting the optimal parameters in a technologic process, as well as establishing the interactions between variables. Taguchi experimental design method is a mathematical and statistical tool for organizing and systematization the experiment, aimed at obtaining the optimum parameters in terms of performance/cost. This method allows the analysis of a large number of variables in a reduced series of the experiments, by using the orthogonal matrix.

The purpose of this study is to obtain AC from the walnut shells by chemical activation and microwave treatment. Taguchi optimization method was employed to determine the optimum parameters for obtaining the AC. The structural and adsorption parameters of obtained AC were also determined.

\section{Experimental \\ Materials}

Walnut shells of local origin were used as raw material for obtaining the AC. Phosphoric acid (85 wt.\%) of analytical grade was used as activating agent. Nitrogen (4.0 purity grade) was used to maintain the inert atmosphere during the activation process and recording the thermograms.

\section{Preparation of AC}

The walnut shells were crushed and separated into three fractions: $0.8-2.0 \mathrm{~mm} ; 2.0-3.15 \mathrm{~mm} ; 3.15-5.0 \mathrm{~mm}$; the non-crushed walnut shells were also used. Shells $(5.0 \mathrm{~g})$ were mixed with $10 \mathrm{~mL}$ of phosphoric acid (40-85 wt.\%) and allowed to contact at room temperature for 24 hours. Thereafter, the mixture of acid and shells was transferred to the quartz reactor and subjected to the activation process. During the activation process and before cooling the carbons 
nitrogen with flow rate $100 \mathrm{~cm}^{3} /$ min has been passed through the reactor. After cooling the AC was washed with a solution of $\mathrm{KOH}(0.05 \mathrm{M})$, hot and cold distilled water until the $\mathrm{pH}$ value of washing solution (6-7). Then AC samples were dried at $110^{\circ} \mathrm{C}$ to the constant mass.

\section{Optimization the conditions for AC preparation}

In order to optimize conditions for obtaining the AC, Taguchi experimental design method was used. Application of Taguchi method involves the following steps:

1. Selection of the final product control parameters;

2. Selection of independent variables and their limits of variation;

3. Choosing the appropriate model of the orthogonal matrix, based on the number of variables;

4. Performing the experiment on the base of orthogonal matrix;

5. Analysis of the obtained results;

6. Conducting the control experiment.

An $\mathrm{L}_{16}$ orthogonal array with four operational parameters each in four levels was used to evaluate the corresponding optimal values. The used variables and their levels are shown in Table 1 . The complete design matrix of the experiments and the obtained results are shown in Table 2 . An $\mathrm{L}_{16}$ orthogonal array was chosen with four operational parameters known as control factors, namely the microwave power $(A)$, the activation time $(B)$, the concentration of phosphoric acid $(C)$ and the fraction of the walnut shells $(D)$. The studied parameters and their limits of variation were chosen based on preliminary experiments and analysis of the literature data. As control parameters specific surface area $\left(S_{B E T}\right)$ and yield of obtained AC were chosen. As a result of data processing, the optimal parameters were obtained and the control activated carbon was synthesized (run 17, Table 2). Data processing of the optimization experiment was carried out in the program Design-Expert Software version 7.0.

Table 1

Levels of the used as preparation parameters control factors.

\begin{tabular}{cccccc}
\hline Independent value & Symbol & \multicolumn{3}{c}{ Range and levels } \\
\cline { 3 - 6 } & & 1 & 2 & 3 & 4 \\
\hline Microwave power, W & $A$ & 450 & 600 & 700 & 850 \\
\hline Activation time, minutes & $B$ & 5 & 10 & 15 & 20 \\
\hline $\mathrm{H}_{3} \mathrm{PO}_{4}$ concentration, wt. $\%$ & $\mathrm{C}$ & 40 & 55 & 70 & 85 \\
\hline Fraction, mm & $D$ & whole shells & $3.15-5.0$ & $2.0-3.15$ & $0.80-2.0$ \\
\hline
\end{tabular}

Table 2

$L_{16}$ orthogonal array of Taguchi method used in the preparation of AC.

\begin{tabular}{ccccccc}
\hline Run & & \multicolumn{2}{c}{ Variables } & \multicolumn{3}{c}{ Responses } \\
\cline { 2 - 6 } & $A$ & $B$ & $C$ & $D$ & $\begin{array}{c}S_{B E T} \\
m^{2} / g\end{array}$ & $\begin{array}{c}\text { Yield of the } \\
\text { AC, }\end{array}$ \\
\hline 1 & 1 & 1 & 1 & 1 & 406.1 & 33.4 \\
\hline 2 & 1 & 2 & 2 & 2 & 600.8 & 39.1 \\
\hline 3 & 1 & 3 & 3 & 3 & 623.2 & 40.4 \\
\hline 4 & 1 & 4 & 4 & 4 & 793.3 & 47.8 \\
\hline 5 & 2 & 1 & 2 & 3 & 588.2 & 39.1 \\
\hline 6 & 2 & 2 & 1 & 4 & 647.5 & 35.5 \\
\hline 7 & 2 & 3 & 4 & 1 & 441.9 & 42.1 \\
\hline 8 & 2 & 4 & 3 & 2 & 636.9 & 39.1 \\
\hline 9 & 3 & 1 & 3 & 4 & 851.6 & 44.8 \\
\hline 10 & 3 & 2 & 4 & 3 & 367.1 & 46.1 \\
\hline 11 & 3 & 3 & 1 & 2 & 467.5 & 35.7 \\
\hline 12 & 3 & 4 & 2 & 1 & 598.6 & 26.3 \\
\hline 13 & 4 & 1 & 4 & 2 & 349.9 & 51.9 \\
\hline 15 & 4 & 3 & 2 & 4 & 709.2 & 42.6 \\
\hline 16 & 4 & 4 & 1 & 3 & 619.3 & 31.4 \\
\hline $\mathbf{1 7}$ & $\mathbf{1}$ & $\mathbf{4}$ & $\mathbf{3}$ & $\mathbf{4}$ & $\mathbf{9 1 7 . 7}$ & 39.5 \\
\hline
\end{tabular}

\section{Analysis of variance}

Identification of the most effective parameters for AC preparation was performed by using analysis of variance (ANOVA) technique [10]. This statistical method does not directly analyze the obtained data, but determine their dispersion. In the analysis of variance, many parameters, such as degrees of freedom, sums of squares, mean square [10], 
and so on, are computed and organized in a standard tabular format. These parameters and their mathematical relations are presented in Table 3.

Table 3

ANOVA terms and notations [10].

\begin{tabular}{|c|c|c|}
\hline ANOVA terms & Description of parameter & Mathematical relation \\
\hline $\mathrm{n}$ & $\begin{array}{l}\text { number of trials, the total number of trials is the sum of the } \\
\text { number of trials at each level }\end{array}$ & $n=n_{1}+n_{2}+\ldots+n_{L}$ \\
\hline $\mathrm{r}$ & number of repetitions & - \\
\hline $\mathrm{Y}$ & response & - \\
\hline$Y_{m}$ & $Y_{m}$ is the average value of $Y$ & \\
\hline $\mathrm{T}$ & total of all results & $T=Y_{1}+Y_{2}+\ldots+Y_{n}$ \\
\hline C.F. & correction factor & C.F. $=T^{2} / n$ \\
\hline $\begin{array}{l}\text { Degrees of freedom } \\
\text { (DOF) }\end{array}$ & $\begin{array}{l}\text { it is a measure of the amount of information that can be uniquely } \\
\text { determined from a given set of data }\end{array}$ & $f_{t}=n * r-1$ \\
\hline Sum of squares, $\mathrm{S}$ & $\begin{array}{l}\text { it is a measure of the deviation of the experimental } \\
\text { data from the mean value of the data }\end{array}$ & $\begin{array}{l}S=\sum_{i=1}^{n}\left(Y_{i}-Y_{m}\right)^{2} \\
\quad \sum_{i=1}^{n}\left(Y_{i}-Y_{m}\right)^{2}\end{array}$ \\
\hline $\begin{array}{l}\text { Total sum of squares, } \\
\qquad \mathrm{S}_{\mathrm{T}}\end{array}$ & $\begin{array}{l}\text { gives an estimate of the sum of the variations of the individual } \\
\text { observations about the mean, } \mathrm{Y} \text {, of the experimental data }\end{array}$ & $\begin{array}{c}S_{T}=\sum_{i=1}^{n} Y_{i}^{2} \sum_{i=1}^{n} Y_{i}^{2} \\
- \text { C.F. }\end{array}$ \\
\hline $\begin{array}{l}\text { Mean square } \\
\text { (variance), } V \\
\mathrm{~V}_{\mathrm{T}} \\
\mathrm{V}_{\mathrm{m}} \\
\mathrm{V}_{\mathrm{e}}\end{array}$ & $\begin{array}{l}\text { Variance measures the distribution of the data about the mean of } \\
\text { the data. } \\
\text { total variance } \\
\text { mean variance } \\
\text { error variance }\end{array}$ & $\begin{array}{c}V=S / f \\
V_{T}=S_{T} / f_{T} \\
V_{m}=S_{m} / f_{m} \\
V_{e}=\left(S_{T}-S_{m}\right) / f_{e}\end{array}$ \\
\hline Variance ratio, $\mathrm{F}$ & $\begin{array}{l}\text { commonly called the } F \text { statistic, is the ratio of variance due to the } \\
\text { effect of a factor and variance due to the error term }\end{array}$ & $F=V_{m} / V_{e}$ \\
\hline Prob $>F$ & $\begin{array}{l}\text { Probability of the observed F value. Small probabilities (less than } \\
0.05 \text { ) indicate that there is a model effect; large values (greater } \\
\text { than } 0.10 \text { ) suggest no significant effect. }\end{array}$ & \\
\hline $\begin{array}{c}\text { Percentage } \\
\text { contribution, } \mathrm{P}\end{array}$ & The percent contribution for any factor & $P=S / S_{T} * 100$ \\
\hline
\end{tabular}

\section{Thermal analysis}

Thermal analysis was performed on Derivatograph Q-1000 system. The samples were placed in a platinum crucible. Each sample (about $50 \mathrm{mg}$ ) was heated under nitrogen flow rate of $100 \mathrm{~mL} / \mathrm{min}$ and a heating rate of $10^{\circ} \mathrm{C} / \mathrm{min}$ from 20 to $1000^{\circ} \mathrm{C}$. Thermogravimetric (TG), derivative weight loss (DTG) and differential thermal (DTA) curves were simultaneously registered.

\section{Gas adsorption characterization}

Structure and adsorption parameters of AC were obtained from nitrogen adsorption isotherms at $77 \mathrm{~K}$. The adsorption isotherms were measured using Autosorb-1-MP (Quantachrome), with prior degassing at $200^{\circ} \mathrm{C}$ for 12 hours. The specific surface area $\left(S_{B E T}\right)$ was calculated using the Brunauer-Emmett-Teller $(B E T)$ equation. The total pore volume $(V)$ was calculated by converting the amount of $\mathrm{N}_{2}$ gas adsorbed at a relative pressure of 0.99 to equivalent liquid volume of the adsorbate $\left(\mathrm{N}_{2}\right)$. The volume of micropores $\left(V_{m i}\right)$ was determined using the $t$-method, the volume of mesopores $\left(V_{m e}\right)$ was determined from the difference of total volume and the volume of micropores. The DubininRadushkevich $(D R)$ method was used to calculate the adsorption energy $\left(E_{\alpha}\right)$. The Density Function Theory $(D F T)$ was used to calculate the pore volume distribution as a function of radius and effective radius $\left(r_{e f}\right)$.

\section{Surface morphology}

The surface physical morphology of AC was identified by using scanning electron microscopy (SEM) technique. A TESCAN Vega TS 5130MM with a $30 \mathrm{kV}$ accelerating voltage was used. Prior to SEM analysis AC sample was dried at $110^{\circ} \mathrm{C}$ under vacuum.

\section{Results and discussion \\ Thermal analysis}

With the purpose of determination the changes occurring in the walnut shells activation process, the thermal analysis of the intact and impregnated with phosphoric acid shells was performed (Figure 1a, b). The main components of the walnut shells are lignin, cellulose and hemicelluloses. Mass fraction of the components, based on the literature data $[11,12]$, is presented in Table 4 . As it can be noted, about $50 \%$ by weight of walnut shells consists of lignin. Being 
a three-dimensional polymer, lignin is also the most thermally stable component of the wood [13]. This leads to the increased efficiency of the process of obtaining the activated carbons [14] and gives them a high mechanical stiffness.

Thermal decomposition of the walnut shells in a nitrogen atmosphere occurs in several steps, Figure 1a. The first step, in the temperature range of $28-150{ }^{\circ} \mathrm{C}$, leads to a decrease in mass of $7.1 \%$ that occurs due to the loss of water and volatile substances. From $200{ }^{\circ} \mathrm{C}$ is observed the next stage on the TG curve, which is explained by the beginning the decomposition of the less thermally stable component, hemicellulose. Thermal degradation continues until $323{ }^{\circ} \mathrm{C}$, with a maximum at $286^{\circ} \mathrm{C}$, this leads to a mass loss of $24.4 \%$ and is accompanied by an exothermic heat effect. The decomposition process of cellulose, which starts at $323{ }^{\circ} \mathrm{C}$ and ends at $390{ }^{\circ} \mathrm{C}$, with a peak at $356{ }^{\circ} \mathrm{C}$, is also accompanied by an exothermic effect. This leads to a loss of $24.11 \%$ in mass. Further heating occurs with a slow loss of weight, which is caused by the thermal degradation of lignin. It should be noted, that lignin decomposes into a wide temperature range between $200-900{ }^{\circ} \mathrm{C}$ [15] and thermal degradation continuous in parallel with hemicelluloses and cellulose. At $1000{ }^{\circ} \mathrm{C}$, the total loss in mass constitutes $70.9 \%$.

However the impregnated with phosphoric acid walnut shells demonstrate different thermal decomposition, Figure $1 \mathrm{~b}$. The presence of phosphoric acid moves the start of process to the lower temperatures. This can be explained by the fact that phosphoric acid promotes the dehydration of wood mass and simultaneously decrease mass fraction of volatile organic substances [16], by this leading to the increase of the yield of final product.
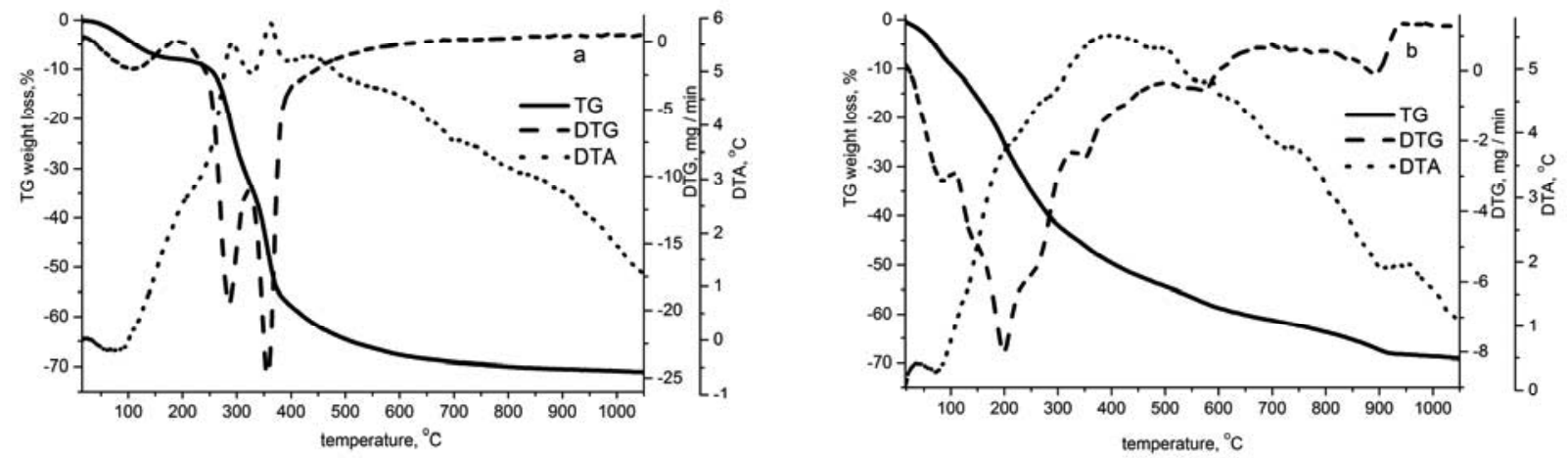

Figure 1. TG-DTG-DTA analysis curves of walnut shells (a) and $\mathrm{H}_{3} \mathrm{PO}_{4}$-impregnated walnut shells (b).

Table 4

Lignocellulose content of walnut shells.

\begin{tabular}{ccccc}
\hline Hemicelluloses, $\%$ & Cellulose, $\%$ & Lignin, $\%$ & Ash, $\%$ & Reference \\
\hline 22.1 & 25.6 & 52.3 & 2.8 & {$[11]$} \\
\hline 22.45 & 26.87 & 47.68 & 0.94 & {$[12]$} \\
\hline
\end{tabular}

\section{Optimization of the activation process}

\section{Preliminary analysis of parameters for obtaining the $A C$}

There are quite a lot of factors that influence the AC parameters, to be analyzed in one series of experiments. Amongst possible factors the following can be listed: activating agent, raw material, time and contact temperature of the raw material with the activating agent, concentration of the activating agent, weight ratio: raw material/activating agent, mass of raw material, size of the particles of raw material, microwave power, activation time, flow rate of nitrogen in the process of activation etc. Along with the above-listed factors, which can easily controlled, there are more difficult to optimize factors, such as the geometry and material from which the reactor is made, position of the reactor in the microwave oven and others.

Since Taguchi method requires only the use of independent variables, at the initial stage it is necessary to choose the optimal value of the dependent variables. Examples of dependent variables can be the mass of raw material and of activating agent, with respect to the microwave power. Concentration of the activating agent is also a dependent variable, because changing the concentration implies the change of dielectric constant of mixture and therefore, its ability to absorb microwaves. However, in the present study no account was taken on this. Another reason why some preliminary experimental data are required is to establish the main and secondary factors.

In order to determine the optimal ratio of walnut shells/activating agent, a series of activated carbons were prepared. The parameters of produced AC are listed in Table 5.

As evidenced by Table 5, increasing the mass of walnut shells, specific surface area of the produced AC tends to decrease at the same ratio of raw material/activating agent. Thus, the best parameters were obtained for the ratio 1:2 
of raw material/activating agent and walnut shells mass of $5 \mathrm{~g}$. Taking into account these data, for optimizing the process of obtaining the $\mathrm{AC}, 5 \mathrm{~g}$ of walnut shells and $10 \mathrm{~mL}$ of phosphoric acid of different concentrations were employed.

Table 5

Activation conditions and parameters of AC obtained preliminary.

\begin{tabular}{|c|c|c|c|c|c|c|c|c|c|c|}
\hline $\begin{array}{c}\text { Ratio } \\
m(A C) / \\
V\left(H_{3} P_{4}\right)\end{array}$ & Run & $\begin{array}{c}\text { Mass } \\
\text { AC, } \\
g\end{array}$ & $\begin{array}{c}\text { Volume } \\
\mathrm{H}_{3} \mathrm{PO}_{4}, \\
\mathrm{~mL}^{2}\end{array}$ & $\begin{array}{c}\mathrm{C} \\
\mathrm{H}_{3} \mathrm{PO}_{4}, \\
\text { wt.\% }\end{array}$ & $\begin{array}{c}\text { Fraction } \\
\qquad \mathrm{mm}\end{array}$ & $\begin{array}{c}\text { Contact } \\
\text { time } \\
h\end{array}$ & $\begin{array}{c}\text { Power of } \\
\text { microwave, } \\
W\end{array}$ & $\begin{array}{c}\text { Time of } \\
\text { activation, } \\
\text { min }\end{array}$ & $\begin{array}{c}\text { Yield, } \\
\%\end{array}$ & $\begin{array}{c}\text { Surface, } \\
m^{2} / g\end{array}$ \\
\hline \multirow{3}{*}{$\ddot{\ddot{ت}}$} & 1 & 5.01 & 5.00 & 85 & $2.0-3.15$ & 24 & 600 & 15 & 37.5 & 606 \\
\hline & 2 & 10.01 & 10.00 & 85 & $2.0-3.15$ & 24 & 600 & 15 & 42.1 & 617 \\
\hline & 3 & 5.02 & 10.00 & 85 & $2.0-3.15$ & 24 & 600 & 15 & 38.6 & 686 \\
\hline \multirow{3}{*}{$\stackrel{N}{\check{-}}$} & 4 & 10.01 & 20.00 & 85 & $2.0-3.15$ & 24 & 600 & 15 & 42.2 & 535 \\
\hline & 5 & 15.00 & 30.00 & 85 & $2.0-3.15$ & 24 & 600 & 15 & 45.9 & 522 \\
\hline & 6 & 20.01 & 40.00 & 85 & $2.0-3.15$ & 24 & 600 & 15 & 42.3 & 475 \\
\hline \multirow{2}{*}{$\stackrel{\sharp}{\ddot{\sim}}$} & 7 & 5.00 & 20.00 & 85 & $2.0-3.15$ & 24 & 600 & 15 & 40.4 & 568 \\
\hline & 8 & 10.01 & 40.00 & 85 & $2.0-3.15$ & 24 & 600 & 15 & 39.4 & 516 \\
\hline
\end{tabular}

The results obtained by statistical processing of the experimental data are presented in Table 6. ANOVA for specific surface has shown results with a lower error in the case when the power of microwave was not taken into consideration. The method allows omission of some parameters in favour of obtaining the greater signal-to- noise ratio.

ANOVA results indicate that fraction of raw material has the greatest influence $(51.8 \%)$ on the specific surface area of $\mathrm{AC}$, the second parameter in terms of significance (36.9\%) being concentration of phosphoric acid. The yield of the $\mathrm{AC}$ is directly influenced by the concentration of acid (51.8\%) and the fraction of carbon $(34 \%)$.

Table 6

Analysis of the variance of main factors for AC production.

\begin{tabular}{cccccccc}
\hline & Parameter & $S^{a}$ & $D O F^{b}$ & $V^{c}$ & $F^{d}$ & Prob $>F^{e}$ & $P^{f}, \%$ \\
\hline \multirow{2}{*}{$\begin{array}{c}\text { ANOVA } \\
\text { of the surface } \\
\text { area }\end{array}$} & Time of activation & 31837.74 & 3 & 10612.58 & 1.83 & 0.24 & 11.3 \\
\cline { 2 - 7 } & Concentration $\mathrm{H}_{3} \mathrm{PO}_{4}$ & 104400 & 3 & 34812.97 & 5.99 & 0.030 & 36.9 \\
\cline { 2 - 7 } $\begin{array}{c}\text { ANOVA of } \\
\text { the activated } \\
\text { carbon yield }\end{array}$ & Fraction & 146300 & 3 & 48751.14 & 8.39 & 0.014 & 51.8 \\
\cline { 2 - 7 } & Power of microwave & 8.82 & 3 & 2.94 & 0.59 & 0.66 & 1.2 \\
\cline { 2 - 7 } & Time of activation & 94.40 & 3 & 31.47 & 6.34 & 0.081 & 13.0 \\
\cline { 2 - 7 } & Concentration $\mathrm{H}_{3} \mathrm{PO}_{4}$ & 377.25 & 3 & 125.75 & 25.32 & 0.012 & 51.8 \\
\hline & Fraction & 247.27 & 3 & 82.42 & 16.60 & 0.022 & 34.0 \\
\hline
\end{tabular}

$a_{-}$sum of squares,

${ }^{b}$ - degrees of freedom,

c- variance,

d- variance ratio,

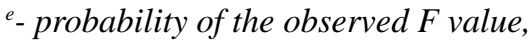

f- percentage contribution.

These data can be explained by the following: the smaller are the particles of raw material, the deeper phosphoric acid penetrates into the volume of walnut shells, which results in a more homogeneous activation, thereby resulting in a larger surface area. At the same time, increasing the concentration of phosphoric acid prevents the formation of volatile compounds, which is consistent with an increase in the yield of the AC. Obtained data are well-correlated with those taken from the thermal analysis.

At the same time, ANOVA indicates that not all variables have a significant contribution to the activation process of carbons. The microwave power and activation time demonstrate low influence on the AC final parameters. A plausible explanation of this is supported by the limits of variation of these parameters, which have been taken in excess, namely for a mass of 5 grams of the raw material the process of activation with microwave takes a small time interval and do not need a high power microwave. Indeed, during the activation of carbons it was noted that after 5 minutes of microwave treatment the amount of emitted smoke is negligible; at the same time this period is sufficient to reach the maximum temperature, regardless of microwave power. Literature data also indicate that augmentation the microwave power and time of activation lead either to decrease or to insignificant changes of AC parameters $[17,18]$. 
Graphical representation of the influence of variables on the yield and specific surface area is shown in Figure 2. Microwave power has the same effect on both parameters: increase of the microwave power leads to the decrease of surface and to the $\mathrm{AC}$ yield. The observed effect takes place due to rapid dynamics of heating the raw material under microwave treatment at higher power levels. It favours the appearance of a greater temperature gradient within the material particles and evaporation of phosphoric acid before it starts to react; volatiles quickly evaporate and do not take part in formation of the AC structure. All these phenomena lead to a diminution of yield and surface of the AC.

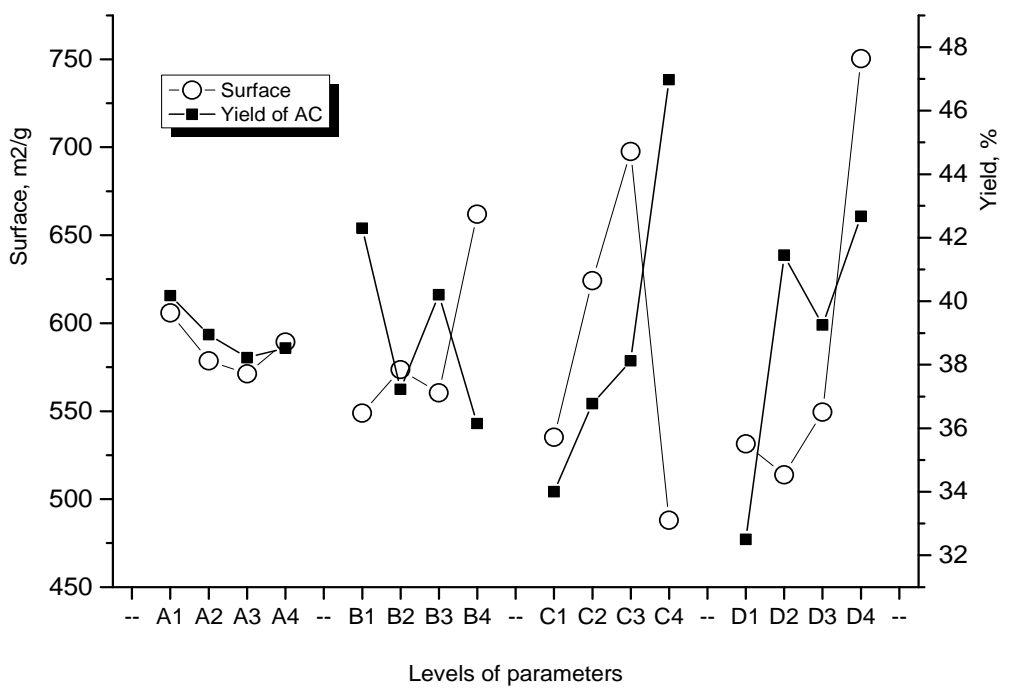

Figure 2. The effect of operational parameters on responses of the prepared AC samples.

\section{Experimental verification of the obtained optimal values}

The provided in Figure 2 data allowed us to establish the optimum parameters for obtaining AC. As it can be seen, there is not a unique solution for obtaining maximum values for both parameters: for specific surface area and yield the optimal conditions are different. Since the initial purpose was to obtain the AC with enhanced values of adsorption parameters, optimization of the process was performed for specific surface area. Based on Figure 2, these parameters are: microwave power - 450W (A1), activation time - 20 minutes (B4), phosphoric acid concentration - 70 wt.\% (C3) and particle size of walnut shells in the range of 0.8-2.0 mm (D4).

Table 7 offers the modelled values of the analyzed system, as well as experimentally obtained ones. C.V. is the coefficient of variation for this model. It is the error expressed as a percentage of the mean. Adequate precision is a measure of the range in predicted response relative to its associated error, in other words a signal to noise ratio. Its desired value is 4 or more. For both parameters this value is more than 4 , indicating on a satisfactory signal. The concordance of the model (C.M.) represents the deviation of the experimental values from the predicted ones and, as one can notice, these values do not exceed the range in predicted response (C.V.).

Table 7

Predicted values of AC for optimal conditions.

\begin{tabular}{cccccc}
\hline Parameter & Prediction & $\begin{array}{c}\text { C.V., } \\
\%\end{array}$ & $\begin{array}{c}\text { Adequate } \\
\text { precision }\end{array}$ & Experiment & $\begin{array}{c}\text { C.M., } \\
\%\end{array}$ \\
\hline Specific surface & $937.6 \mathrm{~m}^{2} / \mathrm{g}$ & 13.00 & 7.40 & 917.7 & 2.12 \\
\hline Yield & $40.2 \%$ & 5.72 & 12.74 & 39.5 & 1.74 \\
\hline
\end{tabular}

\section{Characterization of the prepared at optimized conditions AC}

The obtained under the optimum conditions AC was studied in detail by using the method of gas adsorption and electron microscopy with streak.

\section{Gas adsorption}

The adsorption - desorption isotherm of nitrogen on the obtained at optimized values activated carbon (OAC) is presented in Figure 3. The absorption and structure parameters are given in Table 8. 


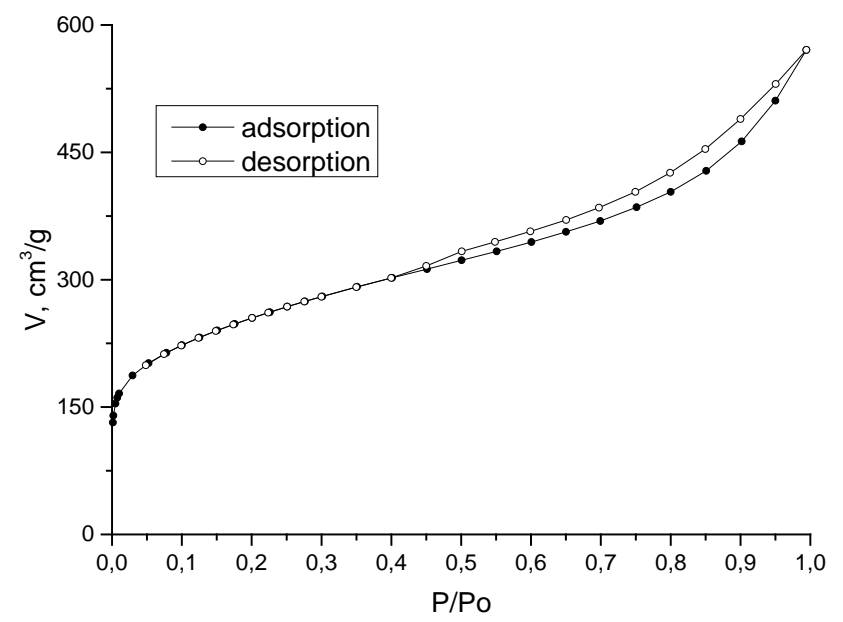

Figure 3. Nitrogen adsorption-desorption isotherm for the prepared at optimum conditions activated carbon.

Structure parameters of the OAC.

\begin{tabular}{ccccccc}
\hline Active carbon & $\begin{array}{c}S_{B E T}, \\
\mathrm{~m}^{2} / g\end{array}$ & $\begin{array}{c}V_{t}, \\
\mathrm{~cm}^{3} / g\end{array}$ & $\begin{array}{c}V_{m,} \\
\mathrm{~cm}^{3} / g\end{array}$ & $\begin{array}{c}V_{m i} \\
\mathrm{~cm}^{3} / g\end{array}$ & $\begin{array}{c}E_{a}, \\
\mathrm{~kJ} / \mathrm{mol}\end{array}$ & $\begin{array}{c}r_{e p} \\
\AA\end{array}$ \\
\hline OAC & 917.7 & 0.883 & 0.701 & 0.182 & 16.8 & 5.6 \\
\hline
\end{tabular}

OAC is a predominantly mesoporous activated carbon with a high specific surface area and a pore size distribution in a wide range (5-60 $\AA$ ), Figure 4 . This makes possible its use in water purification processes, when the size of pollutant molecules have a distribution in a large domain too.

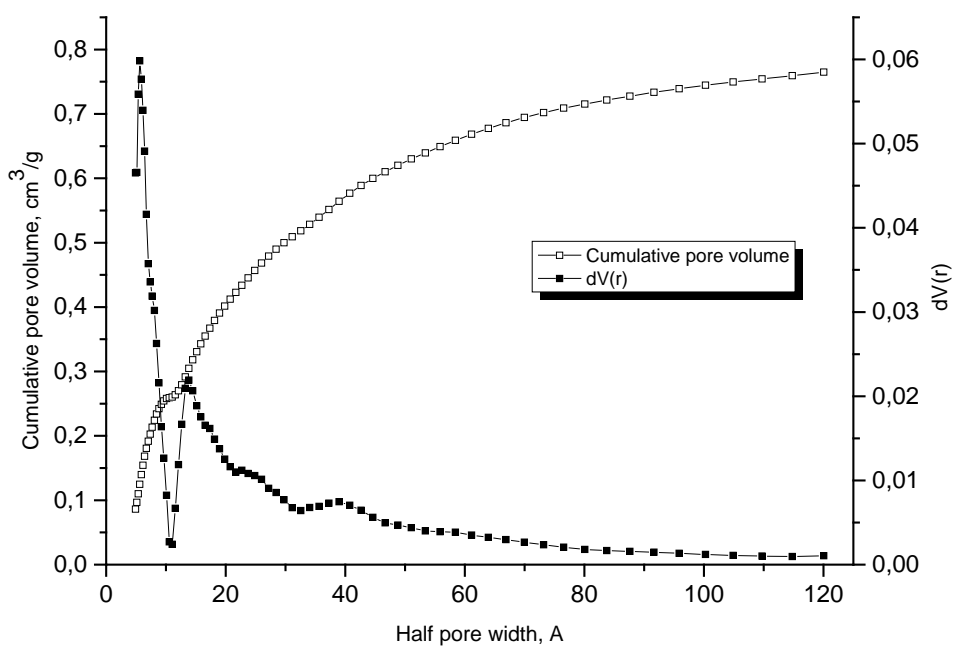

Figure 4. Pore size distributions of OAC by DFT method.

\section{Scanning electron microscopy (SEM)}

Electron microscopy images of the OAC sample are shown in Figure 5. According to them, the OAC surfaces were full of cavities and quite irregular as a result of activation. The external surface of the particles demonstrates an advanced roughness, by this increasing the specific surface area of AC. 


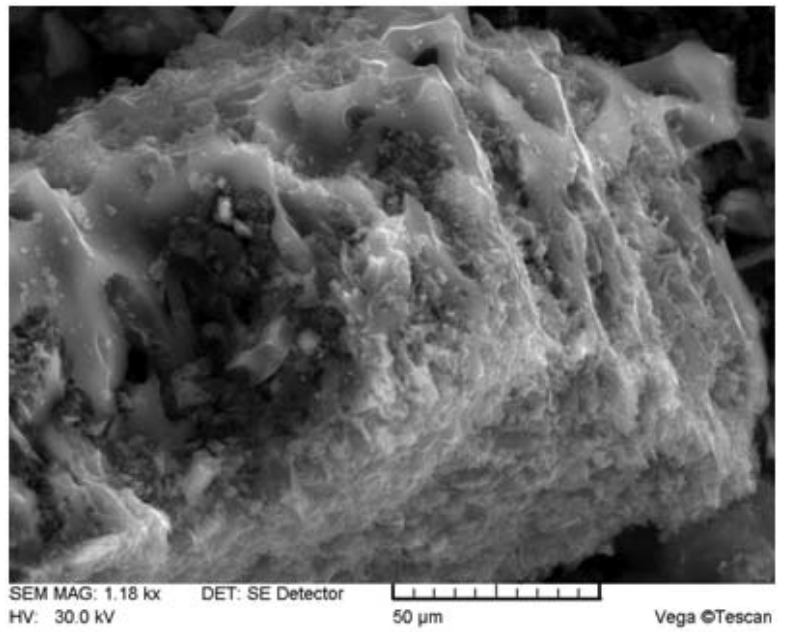

(a)

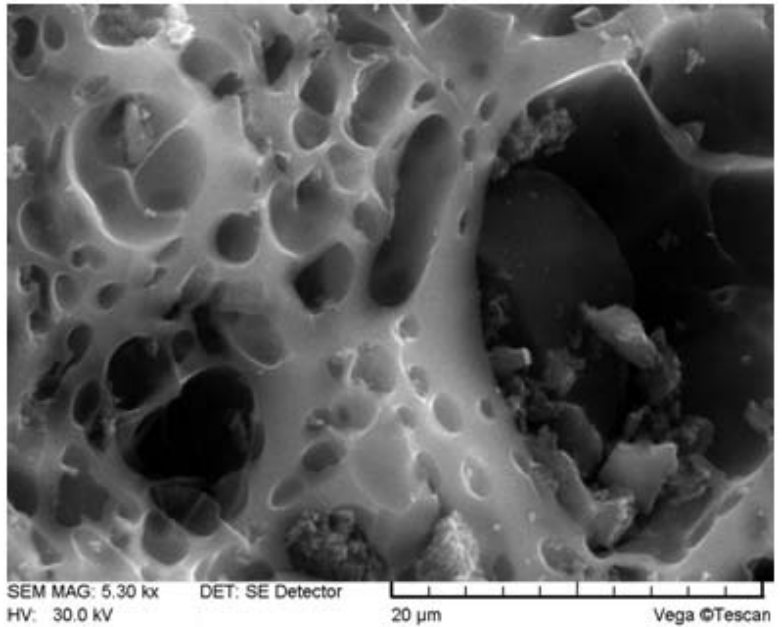

(b)

Figure 5. (a,b) SEM micrographs section of the OAC.

\section{Conclusions}

Taguchi optimization method was employed to establish the optimal conditions for obtaining the activated carbons from walnut shell under microwave treatment. The walnut shells were impregnated at room temperature with phosphoric acid of different concentrations and subjected to microwave irradiation. Particle size of the raw material and concentration of phosphoric acid were found as the factors which influenced most largely the final parameters of activated carbons.

Based on ANOVA results, the optimal parameters for obtaining the activated carbons are: microwave power - 450W, activation time - 20 minutes, concentration of phosphoric acid - $70 \mathrm{wt} . \%$ and shells particle size in the range of 0.8-2.0 $\mathrm{mm}$. The obtained active carbon has mesoporous structure with a large repartition of pores, thereby being possible to use it in the processes of water potabilization. Specific surface area of the obtained under optimum conditions activated carbon constitutes $918 \mathrm{~m}^{2} / \mathrm{g}$ and the yield is $39.5 \%$. Control parameters of the activated carbon correlate very well with those predicted by ANOVA. Taguchi optimization method was proved to be very effective and useful for preparation of the activated carbons.

\section{Acknowledgments}

The research leading to these results has received funding from the People Programme (Marie Curie Actions) of the European Union's Seventh Framework Programme FP7/2007-2013/ under REA grant agreement no. PIRSESGA-2013-612484.

\section{References}

1. Ioannidou, O.; Zabaniotou, A. Agricultural residues as precursors for activated carbon production-A review. Renewable and Sustainable Energy Reviews, 2007, 11(9), pp. 1966-2005.

2. Yagmur, E. Preparation of low cost activated carbons from various biomasses with microwave energy. Journal of Porous Materials, 2012, 19(6), pp. 995-1002.

3. Mui, E. L.; Ko, D. C.; McKay, G. Production of active carbons from waste tyres-a review. Carbon, 2004, 42(14), pp. 2789-2805.

4. Menéndez, J.; Arenillas, A.; Fidalgo, B.; Fernández, Y.; Zubizarreta, L.; Calvo, E.; Bermúdez, J. Microwave heating processes involving carbon materials. Fuel Processing Technology, 2010, 91(1), pp. 1-8.

5. Lam, S. S.; Chase, H. A. A Review on Waste to Energy Processes Using Microwave Pyrolysis. Energies, 2012 , 5(12), pp. 4209-4232.

6. Jones, D.; Lelyveld, T.; Mavrofidis, S.; Kingman, S.; Miles, N. Microwave heating applications in environmental engineering - a review. Resources, Conservation and Recycling, 2002, 34(2), pp. 75-90.

7. Omar, R.; Idris, A.; Yunus, R.; Khalid, K.; Aida Isma, M. Characterization of empty fruit bunch for microwaveassisted pyrolysis. Fuel, 2011, 90(4), pp. 1536-1544.

8. Yang, K. S.; Yoon, Y. J.; Lee, M. S.; Lee, W. J.; Kim, J. H. Further carbonization of anisotropic and isotropic pitchbased carbons by microwave irradiation. Carbon, 2002, 40(6), pp. 897-903. 
9. Li, W.; Peng, J.; Zhang, L.; Yang, K.; Xia, H.; Zhang, S.; Guo, S.-H. Preparation of activated carbon from coconut shell chars in pilot-scale microwave heating equipment at 60kW. Waste Management, 2009, 29(2), pp. 756-760.

10. Ranjit K. Roy. A primer on the Taguchi method, 2nd ed.; Society of Manufacturing Engineers, 2010, 329 p.

11. Demirbaş, A. Fuel Characteristics of Olive Husk and Walnut, Hazelnut, Sunflower, and Almond Shells. Energy Sources, 2010, 24(3), pp. 215-221.

12. Kar, Y. Co-pyrolysis of walnut shell and tar sand in a fixed-bed reactor. Bioresource Technology, 2011, 102(20), pp. 9800-9805.

13. Callum A. S. Hill. Wood Modification: Chemical, Thermal and Other Processes; JohnWiley \& Sons, 2006, 248p.

14. Cagnon, B.; Py, X.; Guillot, A.; Stoeckli, F.; Chambat, G. Contributions of hemicellulose, cellulose and lignin to the mass and the porous properties of chars and steam activated carbons from various lignocellulosic precursors. Bioresource Technology, 2009, 100(1), pp. 292-298.

15. Hu, J.; Shen, D.; Wu, S.; Zhang, H.; Xiao, R. Effect of temperature on structure evolution in char from hydrothermal degradation of lignin. Journal of Analytical and Applied Pyrolysis, 2014, 106, pp. 118-124.

16. Benadjemia, M.; Millière, L.; Reinert, L.; Benderdouche, N.; Duclaux, L. Preparation, characterization and Methylene Blue adsorption of phosphoric acid activated carbons from globe artichoke leaves. Fuel Processing Technology, 2011, 92(6), pp. 1203-1212.

17. Deng, H.; Zhang, G.; Xu, X.; Tao, G.; Dai, J. Optimization of preparation of activated carbon from cotton stalk by microwave assisted phosphoric acid-chemical activation. Journal of Hazardous Materials, 2010, 182(1-3), pp. 217-224.

18. Hejazifar, M.; Azizian, S.; Sarikhani, H.; Li, Q.; Zhao, D. Microwave assisted preparation of efficient activated carbon from grapevine rhytidome for the removal of methyl violet from aqueous solution. Journal of Analytical and Applied Pyrolysis, 2011, 92(1), pp. 258-266. 